Published in final edited form as:

Anal Chem. 2008 February 1; 80(3): 707-712.

\title{
Potentiometric Immunoassay with Quantum Dot Labels
}

\author{
Reto Thuürer ${ }^{\dagger}, \ddagger$, Tamás Vigassy ${ }^{\dagger}$, Martina Hirayama ${ }^{*}, \ddagger$, Joseph Wang ${ }^{*}, \S$, Eric Bakker ${ }^{*}, \|$, and \\ Ernö Pretsch ${ }^{*}, \dagger$ \\ Laboratorium für Organische Chemie, ETH Zürich, CH-8093 Zürich, Switzerland, Departement \\ Technik, Informatik und Naturwissenschaften, Zürcher Hochschule Winterthur, Technikumstrasse \\ 9, $\mathrm{CH}-8400$ Winterthur, Switzerland, The Biodesign Institute and Fulton School of Engineering, \\ Arizona State University, Tempe, Arizona 85287, and Department of Chemistry, Purdue University, \\ West Lafayette, Indiana 47907
}

\section{Abstract}

Potentiometric sensors based on polymer membrane electrodes, if properly optimized, are useful for measurements at trace levels. The expected independence of the electrochemical signal of the sample size makes them extremely attractive for measurements in small volumes. Here, we report on electrodes for the potentiometric detection of cadmium ions that reach a detection limit of $6 \mathrm{nM}$ and utilize a $\mathrm{Na}^{+}$-selective electrode as pseudoreference in order to facilitate measurements in $150-\mu \mathrm{L}$ samples. A potentiometric immunoassay of mouse $\mathrm{IgG}$ is performed via CdSe quantum dot labels on a secondary antibody according to a sandwich immunoassay protocol in a microtiter plate format. The CdSe quantum dots are found to be easily dissolved/oxidized in a matter of minutes with hydrogen peroxide, allowing us to maintain the $\mathrm{pH}$ at a near-neutral value. The potentiometric protein immunoassay exhibits a log-linear response ranging from 0.15 to $4.0 \mathrm{pmol}$ of $\mathrm{IgG}$, with a detection limit of $<10 \mathrm{fmol}$ in $150-\mu \mathrm{L}$ sample wells.

Nanoparticle-based electrochemical protein immunoassays typically employ stripping voltammetric techniques as the readout principle. ${ }^{1-6}$ Upon completion of the protein binding event with a secondary antibody labeled with gold nanoparticles or semiconductor quantum dots, the tracers are detected electrochemically. This may be achieved after an oxidation/ dissolution step with reagents such as nitric acid ${ }^{7}$ or directly with solid-state chronopotentiometry. 8 Alternatively, enzyme labels, known as highly effective biological amplifiers, can be used, for example, in a magnetic collection on interdigitated electrodes. ${ }^{9}$ Recently, carbon nanotubes decorated with multiple enzymes were also used as labels for an even greater chemical amplification of the immunobinding event. ${ }^{10}$

Stripping voltammetric techniques exhibit extremely low lower detection limits in terms of concentration. The measurement of trace level concentrations in microliter or submicroliter volumes has been achieved with nanoband electrodes. In 500-nL sample droplets, the lowest detected concentrations were $0.5 \mathrm{ppb}$ lead with high-amplitude square wave voltammetry, ${ }^{11}$ while the injection of 1.4- $\mu \mathrm{L}$ samples of tear fluid made it possible to measure $6.5 \mathrm{ppb}$ cadmium with anodic stripping voltammetry, ${ }^{12}$ both with mercury film electrodes. In these two examples, the detected total amounts of material were on the order of $2.5 \times 10^{-13}$ and $6.5 \times$

\footnotetext{
* To whom correspondence should be addressed. E-mail: him@zhwin.ch; joseph.wang@ @asu.edu; bakkere@ @urdue.edu; pretsche@ethz.ch.

ETH Zürich.

†Zürcher Hochschule Winterthur.

\$Arizona State University.

|Purdue University.

SUPPORTING INFORMATION AVAILABLE

Additional information as noted in text. This material is available free of charge via the Internet at http://pubs.acs.org.
} 
$10^{-13} \mathrm{~g}$ of lead and cadmium, respectively. More recent efforts aimed at further reducing the detection volume down to $1 \mathrm{~nL}$, but the lowest detected amount of material was somewhat inferior at $7.5 \times 10^{-12} \mathrm{~g} .13$

Potentiometry with ion-selective electrodes (ISEs) is attractive for trace level analysis in confined samples. There exists a direct relationship between sample activity and observed electromotive force, independent of the volume of the sample or electrode surface. Indeed, ionselective microelectrodes have been used for the detection of millimolar concentrations in single cells having volumes on the order of $1 \mathrm{pL} .{ }^{14}$ In recent years, polymer membrane potentiometric sensors have reached ultratrace level detection limits on the order of nanomolar or lower concentrations. ${ }^{15,16}$ This was achieved by understanding and minimizing undesired zero current ion fluxes from the membrane toward the sample, which have traditionally tainted the electrode response. With micropipet-based ISEs, it was recently found that the lower detection limit can be approximately maintained in confined sample volumes. ${ }^{17}$ The detection of $10^{-10} \mathrm{M} \mathrm{Ag}^{+}, \mathrm{Pb}^{2+}$, and $\mathrm{Ca}^{2+}$ was demonstrated in ultrasmall volumes of $3 \mu \mathrm{L}$, resulting in a detectability of 300 amol. ${ }^{17}$

Potentiometric immunoassays have been explored by only a limited number of researchers. Rechnitz and co-workers introduced gas-sensing probes in conjunction with $\mathrm{NH}_{3}$-producing deamination enzymes such as asparaginase as labels ${ }^{18}$ or with the $\mathrm{CO}_{2}$ production from $\beta$ ketoadipic acid by chloroperoxidase enzyme-labeled IgG antibody. ${ }^{19}$ Others used an $\mathrm{I}^{-}$selective electrode to monitor the extent of oxidation of $\mathrm{I}^{-}$by $\mathrm{H}_{2} \mathrm{O}_{2}$ produced by a peroxidase label. ${ }^{20}$ More recently, Koncki and coworkers used a $\mathrm{F}^{-}$-selective electrode for monitoring the release of $\mathrm{F}^{-}$from the substrate monofluorophosphate, catalyzed by the alkaline phosphatase label. ${ }^{21}$ Meyerhoff's group explored polycation-selective electrodes to monitor immunoreactions in a competitive homogeneous assay format. ${ }^{22}$

The recent progress with ISEs described above forms the basis for the application of potentiometric sensors in ultrasensitive bioanalysis using chemical amplification steps. Recently, we reported on the detection of proteins in a potentiometric immunoassay with gold nanoparticle labels that were chemically plated with silver. ${ }^{23}$ The chemically dissolved silver ions were subsequently detected by potentiometry. Here, we explore the detection of $\mathrm{Cd}^{2+}$ with a $\mathrm{Cd}^{2+}$-selective micropipet electrode in a more convenient format, utilizing commercially available CdSe semiconductor quantum dots as labels for protein immunoassays without any further chemical enhancement step, and using microtiter plates as a readout platform. The detection limit is lower by $\sim 3$ orders of magnitude than reported previously. ${ }^{23}$

\section{EXPERIMENTAL SECTION}

\section{Reagents, Membranes, and Electrodes}

See Supporting Information.

\section{Emf Measurements}

Potential measurements were performed with a 24-bit emf measuring interface (EMF-16, Lawson Labs, Malvern, PA) with 1 reference and 16 measuring channels in a Faraday cage. Measurements in conventional $100-\mathrm{mL}$ samples were performed at ambient temperature using a commercial reference electrode (Metrohm, No. 6.0729.100, Metrohm, CH-9101 Herisau) with a $1 \mathrm{M} \mathrm{NH}_{4} \mathrm{NO}_{3}$ electrolyte. Sample $\mathrm{pH}$ values were determined with a $\mathrm{pH}$ glass electrode (No. 6.0133.100, Metrohm). The samples contained an ionic background of $10 \mu \mathrm{M} \mathrm{NaNO}_{3}$ and were magnetically stirred. At least three electrodes of the same membrane composition were used. 
Measurements in microwells were performed with a $\mathrm{Na}^{+}$-selective micropipet electrode as pseudoreference electrode, again keeping a $10 \mu \mathrm{M} \mathrm{NaNO}_{3}$ background in the sample. Samples were stirred with a small stirring bar. Prior to measurement, each well was cleaned in the following order: $300 \mu \mathrm{L}$ of $1 \mathrm{M} \mathrm{HNO}_{3}$ for $15 \mathrm{~min}$ (on shaker), three washing steps with $\mathrm{H}_{2} \mathrm{O}$, $300 \mu \mathrm{L}$ of $1 \%$ BSA for $2 \mathrm{~h}$ (on shaker), three washing steps with $\mathrm{H}_{2} \mathrm{O}, 300 \mu \mathrm{L}$ of $10^{-5} \mathrm{M} \mathrm{Cd}$ $\left(\mathrm{NO}_{3}\right)_{2}+10^{-5} \mathrm{M} \mathrm{NaNO}_{3}$, again followed by three washing steps with $\mathrm{H}_{2} \mathrm{O}$.

Selectivity coefficients were determined with the modified separate solutions method 24,25 with ISEs that had been conditioned in $\mathrm{NaNO}_{3}$ solutions. Emf measurements were carried out in separate solutions of $10^{-2}, 10^{-3}$, and $10^{-4} \mathrm{M}$ nitrate salts of the ions of interest following the order of the most discriminated to the most preferred ion.

\section{Immunoassay}

Sandwich immunoassays were performed according to standard protocols ${ }^{26}$ on commercial ELISA plates (Immuno Module F8 Maxisorp Loose, No. 469949, Nunc, Roskilde, Denmark), which were cleaned as described above. Each well was then coated with $100 \mu \mathrm{L}$ of capture antibody $(7 \mu \mathrm{g} / \mathrm{mL})$ in blocking buffer (PBS at $\mathrm{pH} 7.4$ with $1 \% \mathrm{BSA}$ ) for $12 \mathrm{~h}$ at $4{ }^{\circ} \mathrm{C}$, followed by three washing steps with wash buffer (TRIS-HCl at $\mathrm{pH} 7.4$ with $0.05 \%$ Tween 20 ). Then, $300 \mu \mathrm{L}$ of blocking buffer was applied for $2 \mathrm{~h}$ on the shaker, again followed by three washing steps with wash buffer. Incubation with antigen was performed with $100 \mu \mathrm{L}$ of antigen solution in blocking buffer for $2 \mathrm{~h}$ on the shaker, followed by three washing steps with wash buffer. Negative controls were done without antigen in the blocking buffer. Secondary antibodies were incubated by adding $100 \mu \mathrm{L}$ of quantum dot conjugate $(25 \mathrm{pmol} / \mathrm{mL})$ in blocking buffer for 2 $\mathrm{h}$ on the shaker, followed by three washing steps with wash buffer and five washing steps with $\mathrm{H}_{2} \mathrm{O}$. The final measuring step was performed after incubating $150 \mu \mathrm{L}$ of a $3 \% \mathrm{H}_{2} \mathrm{O}_{2}$ solution in $10^{-5} \mathrm{M} \mathrm{NaNO}_{3}$ for $15 \mathrm{~min}$ on the shaker. All steps were performed at room temperature. Washing solutions were incubated for $30 \mathrm{~s}$ and removed by gently tapping the inverted plate on clean tissue paper. Solutions of capture antibody, secondary antibody, and concentration standards of $\mathrm{IgG}$ were freshly prepared before measurements.

\section{RESULTS AND DISCUSSION}

We have developed micropipet-based $\mathrm{Cd}^{2+}$-selective electrodes suitable for trace measurements of $\mathrm{Cd}^{2+}$ concentrations in $150-\mu \mathrm{L}$ microwells (see Figure 1). Detection limits of $\sim 10^{-10} \mathrm{M} \mathrm{Cd}^{2+}$ were achieved with macroelectrodes and large sample volumes. ${ }^{27}$ The following potentiometric selectivity coefficients, $\log K_{\mathrm{Cd}, j}{ }^{\text {pot }}$, were determined for the relevant cations: $-6.57\left(\mathrm{Na}^{+}\right),-5.91\left(\mathrm{H}^{+}\right)$, and $-10.17\left(\mathrm{Zn}^{2+}\right)$. High selectivity for $\mathrm{Na}^{+}$is required because it is chosen here as the background ion in conjunction with a $\mathrm{Na}^{+}$-selective electrode as pseudoreference. Since $\mathrm{H}_{3} \mathrm{O}+$ are present in every aqueous sample, they may also worsen the detection limit if selectivity is limited. Moreover, $\mathrm{Zn}^{2+}$ will be a byproduct of dissolving the CdSe nanocrystals because they contain a $\mathrm{ZnS}$ capping.

Initial calibration curves in untreated $150-\mu \mathrm{L}$ microwells resulted in a much poorer lower detection limit than that observed in conventional $100-\mathrm{mL}$ samples. A pretreatment protocol was developed (see Experimental Section), and as illustrated in Figure 2, the resulting calibration curves exhibited a detection limit of $\sim 5.6 \times 10^{-8} \mathrm{M} \mathrm{Cd}^{2+}$. This is still less than that with macroscopic samples, which must be due to working with microtiter plates, since much better detection limits have been obtained in samples of $3-\mu \mathrm{L}$ volume with similar ISEs. ${ }^{17}$

The basis for the immunoassay reported here is the potentiometric detection of $\mathrm{Cd}^{2+}$ released from the CdSe nanocrystal labels after completion of the sandwich assay. Conventionally, such quantum dots are effectively oxidized with $\mathrm{HNO}_{3}$ at $\mathrm{pH} \sim 0 .{ }^{7}$ The high concentration of $\mathrm{H}_{3} \mathrm{O}$ + would, however, largely interfere with the potentiometric detection of $\mathrm{Cd}^{2+}$, leading to 
unacceptably high detection limits of $>10^{-6} \mathrm{M} \mathrm{Cd}^{2+}$. Therefore, $\mathrm{H}_{2} \mathrm{O}_{2}$ was used for the oxidation of CdSe quantum dots. Figure 3 shows the potentiometric response of the $\mathrm{Cd}^{2+}$ selective electrode immersed in $150-\mu \mathrm{L}$ wells containing different concentrations of $\mathrm{H}_{2} \mathrm{O}_{2}$. The emf gradually increases upon addition of $\mathrm{CdSe}$ quantum dots and gives final potential readings after $\sim 20$ min when $3 \% \mathrm{H}_{2} \mathrm{O}_{2}$ is used. Note that increasing concentrations of $\mathrm{H}_{2} \mathrm{O}_{2}$ only accelerate the kinetics of dissolution. The potentials before adding the quantum dots and after reaching the dissolution equilibrium are independent of the concentration of the oxidant, suggesting that no direct chemical interference by $\mathrm{H}_{2} \mathrm{O}_{2}$ takes place. A calibration curve for $\mathrm{Cd} 2+$ in a $3 \% \mathrm{H}_{2} \mathrm{O}_{2}$ background using $150-\mu \mathrm{L}$ wells gave a detection limit just below $10^{-7} \mathrm{M}$. The dissolution experiments were also used to estimate the number of cadmium ions per quantum dot nanocrystal as $\sim 500$, which is in reasonable agreement with the stated molar mass of the CdSe core of $200 \mu \mathrm{g} / \mathrm{nmol}$ corresponding to $\sim 1000 \mathrm{Cd}^{2+} /$ quantum dot.

A standard protocol ${ }^{26}$ was adapted for the potentiometric immunoassay (Figure 4). The capture antibody was immobilized on the microwell plate by incubation in a blocking buffer containing BSA. After another blocking step, anti-mouse IgG antigen was incubated, followed by binding with a secondary antibody having a $\mathrm{CdSe}$ nanoparticle label. The quantum dots were dissolved with $\mathrm{H}_{2} \mathrm{O}_{2}$, and the response of the $\mathrm{Cd} 2+$-selective electrode was recorded after $15 \mathrm{~min}$. Experiments with a corresponding colorimetric enzymatic immunoassay showed a similar behavior of the two assays at higher concentrations, suggesting that the upper detection limit is determined by saturation of the captured antibody in the microwell.

The potentiometric response in a typical series of immunoassays with varying concentrations of anti-mouse $\mathrm{IgG}$ antigen is shown in Figure 5. Based on the precision of potentiometric measurements in the applied microtiter plates (Figure 2), the error at $\log \left(\operatorname{IgG}\left[\mu \mathrm{mL}^{-1}\right]\right)-1$ (corresponding to $\sim 10^{-6} \mathrm{M} \mathrm{Cd}^{2+}$ ) can be estimated as $(0.15$ logarithmic units. The dynamic range of the assay is somewhat larger than 2 orders of magnitude. The lower detection limit is better than $10^{-2} \mu \mathrm{g} \mathrm{mL} \mathrm{m}^{-1}$ or $<10 \mathrm{fmol}$ of anti-mouse IgG. A recently introduced potentiometric immunoassay based on Au nanoparticles and Ag labeling exhibited lower detection limits that were higher by $\sim 3$ orders of magnitude than the one presented here. ${ }^{23}$ An advantage of the semiconductor nanocrystal tags used here is that the label is not generated in situ as with silverplated Au nanoparticles, and therefore, nonspecific labeling is less likely. Figure 5 shows that the control containing only BSA as nontarget protein gives a background signal that is lower by several orders of magnitude than with the previously reported protocol.

Using stripping voltammery, a lower detection limit of $3.3 \mathrm{fmol}$ of $\mathrm{Cd}^{2+}$ has been achieved with a related CdS quantum dot based assay. ${ }^{2}$ This indicates that the current bioassay is already quite close to the state of the art achieved with the best available electrochemical techniques. Further improvements of the lower detection limit are expected by using much smaller sample volumes (e.g., $3 \mu \mathrm{L}$ instead of $150 \mu \mathrm{L}$ ), ${ }^{17}$ ISEs with even better lower detection limits $\left(10^{-10} \mathrm{M}\right.$ instead of $\sim 10^{-8} \mathrm{M}$ is feasible $),{ }^{17}$ and/or larger quantum dots.

\section{CONCLUSIONS}

We demonstrated the potentiometric bioanalysis of proteins in a microtiter plate format with semiconductor nanocrystal labels and $<10$-fmol detection limits. This was achieved with $\mathrm{Cd}^{2+}$-selective micropipet electrodes that were optimized to exhibit attractive detection limits in confined sample volumes. The lower detection limit in terms of concentration appears to be dictated by the selectivity of the immunoassay, while the upper detection limit was found to be given by the available binding sites in each microvial. It is anticipated that further reduction of the final detection volume will improve the lower detection limit of such potentiometric bioassays in terms of total analyte mass to an even larger extent. 


\section{Acknowledgements}

The authors are grateful for the National Institutes of Health (EB002189) and The Swiss National Science Foundation for financial support of this research. We thank Dr. D. Wegmann for careful reading of the manuscript.

\section{References}

1. Deqaire M, Degrand C, Limoges B. Anal Chem 2000;72:5521-5528. [PubMed: 11101226]

2. Liu G, Wang J, Kim J, Jan MR. Anal Chem 2004;76:7126-7130. [PubMed: 15571369]

3. Liao KT, Huang HJ. Anal Chim Acta 2005;538:159-164.

4. Chu X, Fu X, Chen K, Shen GL, Yu RQ. Biosens Bioelectron 2005;20:1805-1812. [PubMed: 15681197]

5. Wang J. Analyst 2005;130:421-426. [PubMed: 15846872]

6. Wang, J. Stripping Analysis. VCH; New York: 1985.

7. Authier L, Grossiord C, Brossier P, Limoges B. Anal Chem 2001;73:4450-4456. [PubMed: 11575792]

8. Wang J, Xu D, Polsky R. J Am Chem Soc 2002;124:4208-4209. [PubMed: 11960439]

9. Thomas JH, Kim SK, Hesketh PJ, Halsall HB, Heineman WR. Anal Chem 2004;76:2700-2707. [PubMed: 15144178]

10. Wang J, Liu G, Jan MR. J Am Chem Soc 2004;126:3010-3011. [PubMed: 15012105]

11. Wang J, Rongrong X, Baomin T, Wang J, Renschler CL, White CA. Anal Chim Acta 1994;293:4348 .

12. Matysik FM, Werner G. Analyst 1993;118:1523-1526. [PubMed: 8109755]

13. Vandaveer WR, Fritsch I. Anal Chem 2002;74:3575-3578. [PubMed: 12139070]

14. Ammann, D. Ion-Selective Microelectrodes. Springer-Verlag; Berlin: 1986.

15. Bakker E, Pretsch E. Anal Chem 2002;74:420A-426A. [PubMed: 11811417]

16. Bakker E, Pretsch E. Trends Anal Chem 2005;24:199-207.

17. Malon A, Vigassy T, Bakker E, Pretsch E. J Am Chem Soc 2006;128:8154-8155. [PubMed: 16787077]

18. Gebauer CR, Rechnitz GA. Anal Biochem 1982;124:338-348. [PubMed: 6756206]

19. Fonong T, Rechnitz GA. Anal Chem 1984;56:2586-2590. [PubMed: 6393823]

20. Boitieux JL, Lemay C, Desmet G, Thomas D. Clin Chim Acta 1981;113:175-182. [PubMed: 7249359]

21. Konicki R, Rudnicka K, Tymecki L. Anal Chim Acta 2006;577:134-139. [PubMed: 17723664]

22. Sheng D, Meyerhoff ME. Electroanalysis 2001;13:276-283.

23. Chumbimuni-Torres KY, Zong D, Rubinova N, Xiang Y, Pretsch E, Wang J, Bakker E. J Am Chem Soc 2006;128:13673-13677.

24. Bakker E. Anal Chem 1997;69:1061-1069.

25. Bakker E, Pretsch E, Bühlmann P. Anal Chem 2000;72:1127-1133. [PubMed: 10740849]

26. Wild, DJ. The Immunoassay Handbook. Elsevier; Amsterdam: 2005.

27. Ion AC, Bakker E, Pretsch E. Anal Chim Acta 2001;440:71-79.2002;452:329. 

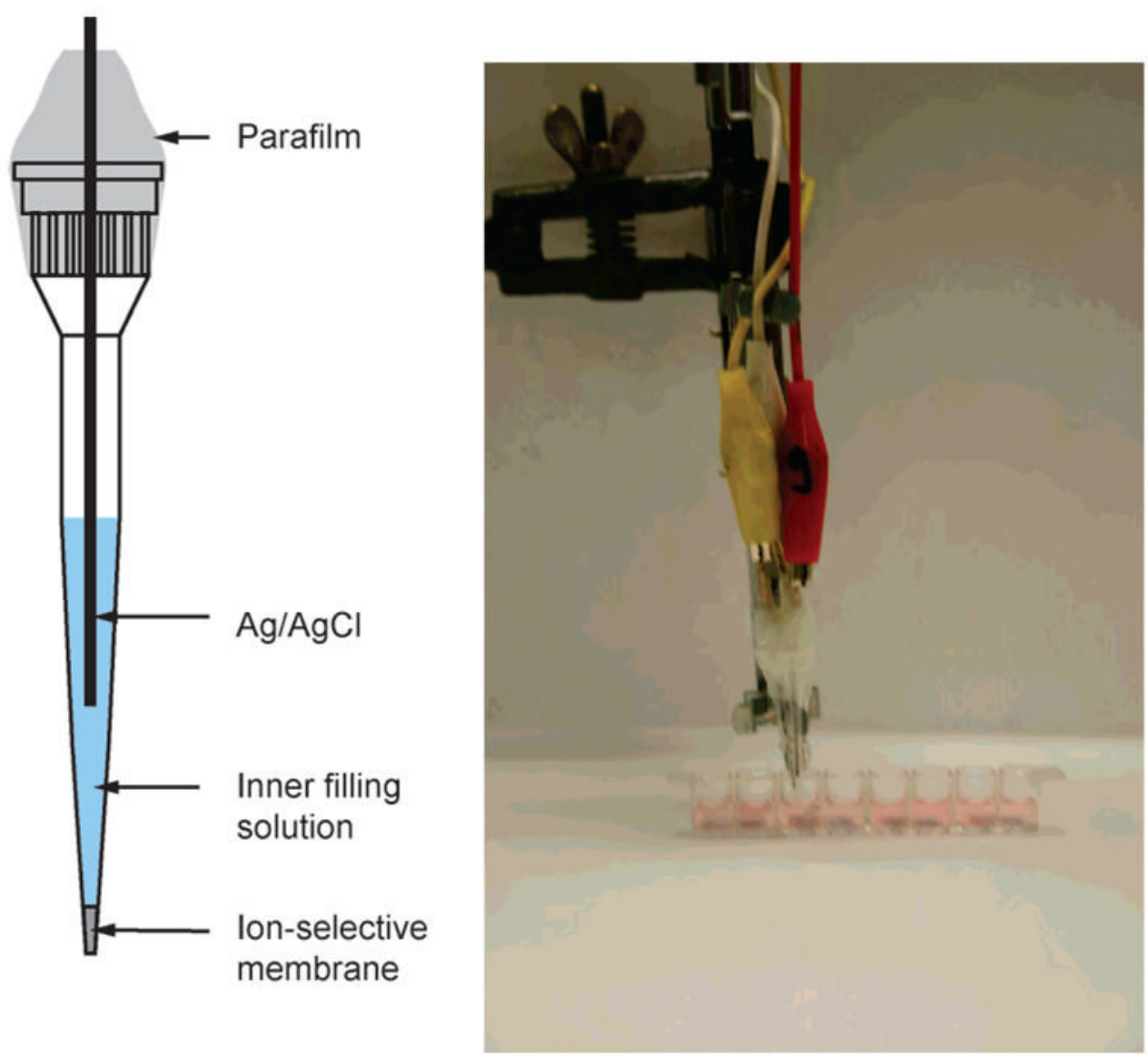

Figure 1.

Left: Design of $\mathrm{Cd}^{2+}$-selective micropipet electrodes. Right: Experimental assembly for potentiometric microtiter plate measurement. 


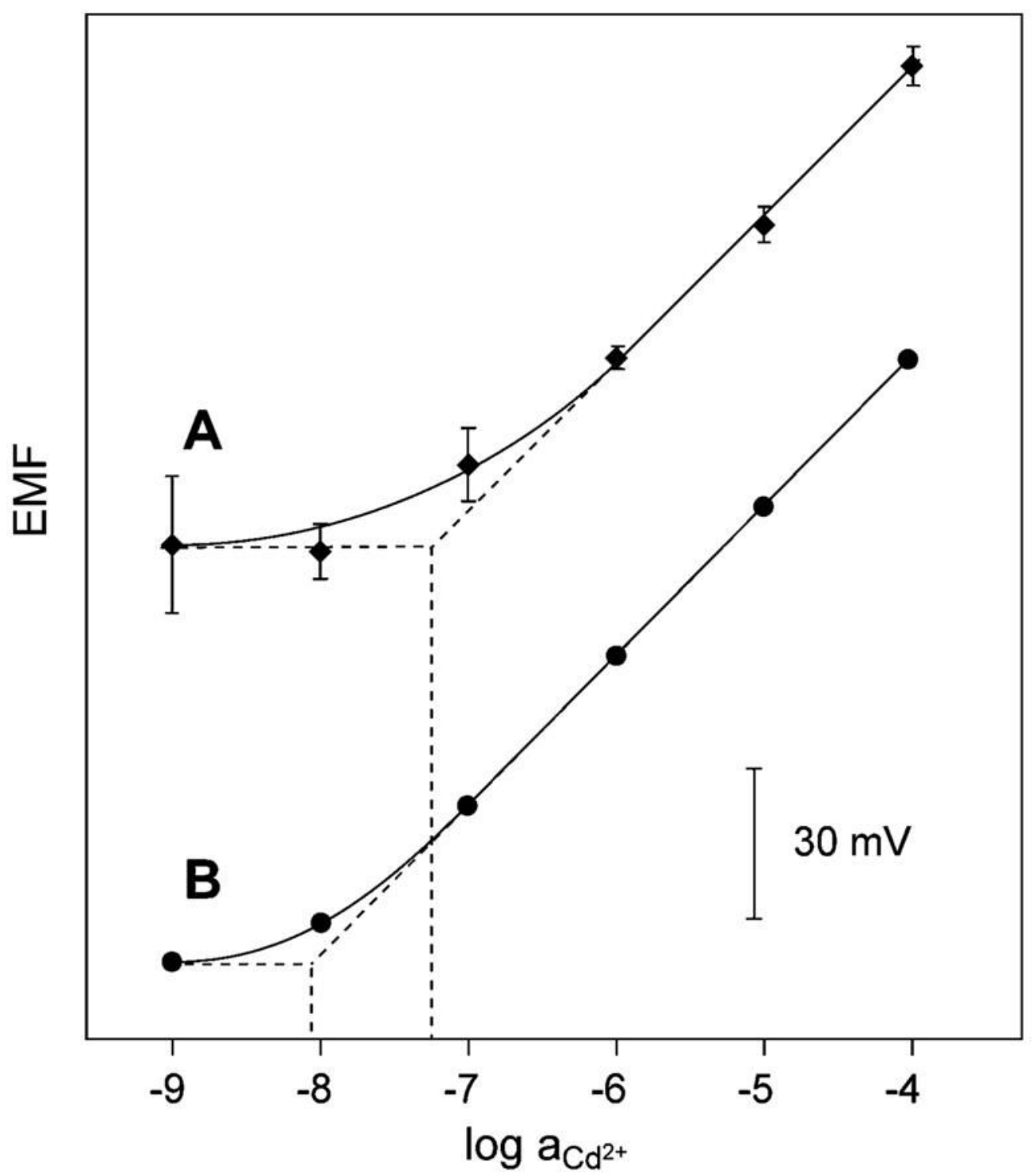

Figure 2.

Calibration curves of $\mathrm{Cd}^{2+}$-selective micropipet electrodes in (A) in $150-\mu \mathrm{L}$ microwells used in the final bioassay and (B) in large, 100-mL sample volumes. Horizontal dotted lines: lower detection limit according to IUPAC definition. Error bars are $90 \%$ confidence intervals in different microwells of the same composition, $N=8$. 


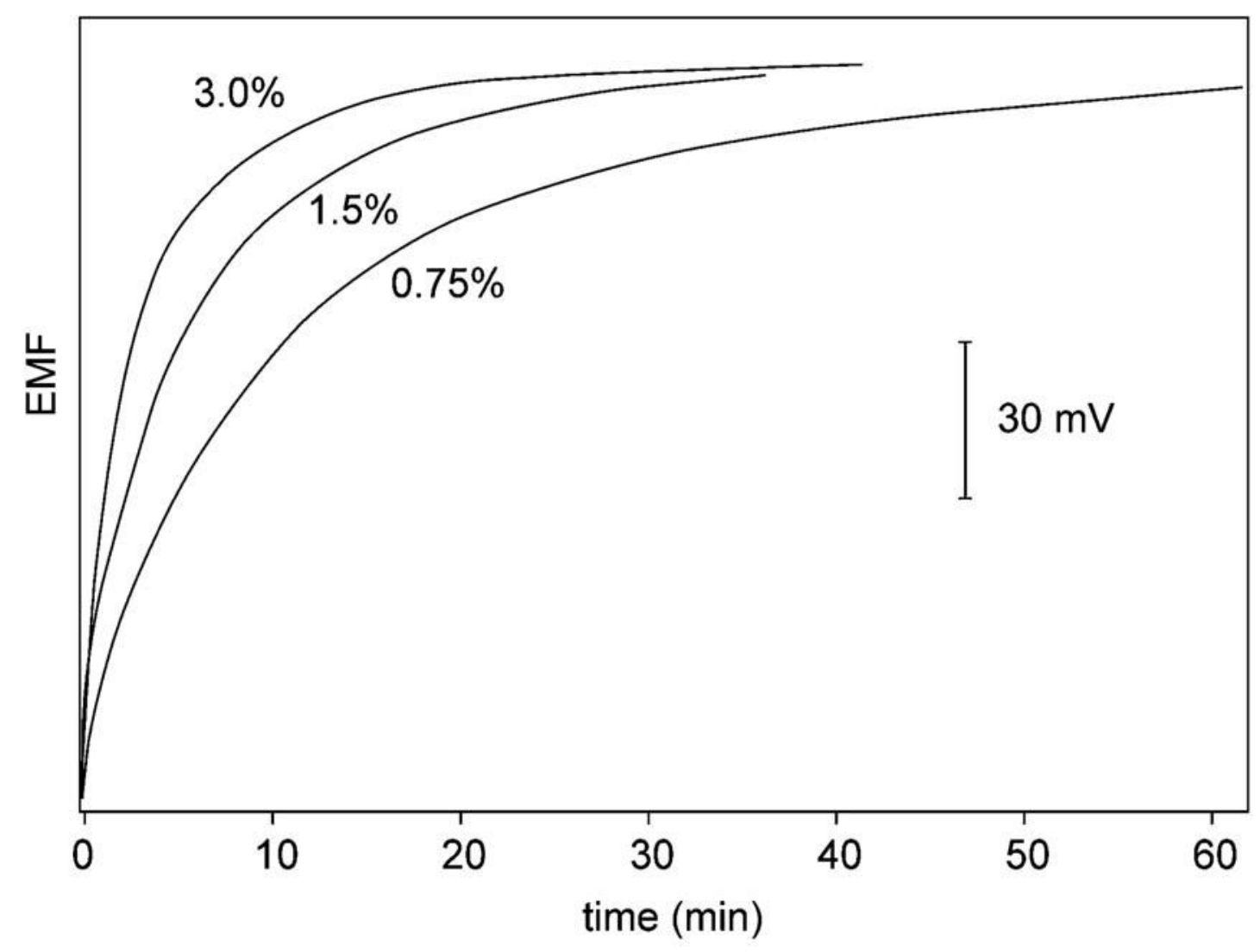

Figure 3.

Time response for the $\mathrm{Cd}^{2+}$-ISE in a $150-\mu \mathrm{L}$ sample well, containing the indicated $\mathrm{H}_{2} \mathrm{O}_{2}$ concentrations (v/v \%), upon addition of $0.18 \mathrm{pmol}$ of quantum dot conjugate. 


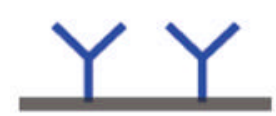

(a)

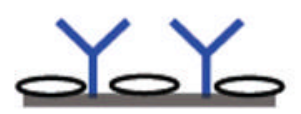

(b)

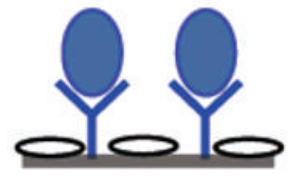

(c)

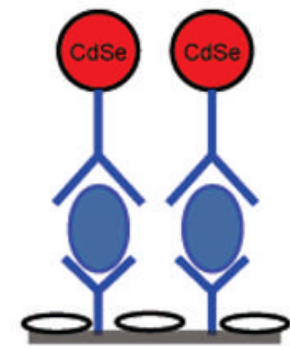

(d)

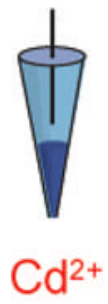

(e)

Figure 4.

Immunoassay protocol used in this study. (a) Antibody is immobilized on a microwell plate, (b) the plate is blocked with BSA, (c) anti-mouse IgG antigen is incubated, (d) the secondary antibody with CdSe nanoparticle labels is bound, and (e) the label is dissolved with $\mathrm{H}_{2} \mathrm{O}_{2}$ and the released $\mathrm{Cd} 2+$ is detected with the $\mathrm{Cd}^{2+}-\mathrm{ISE}$. 


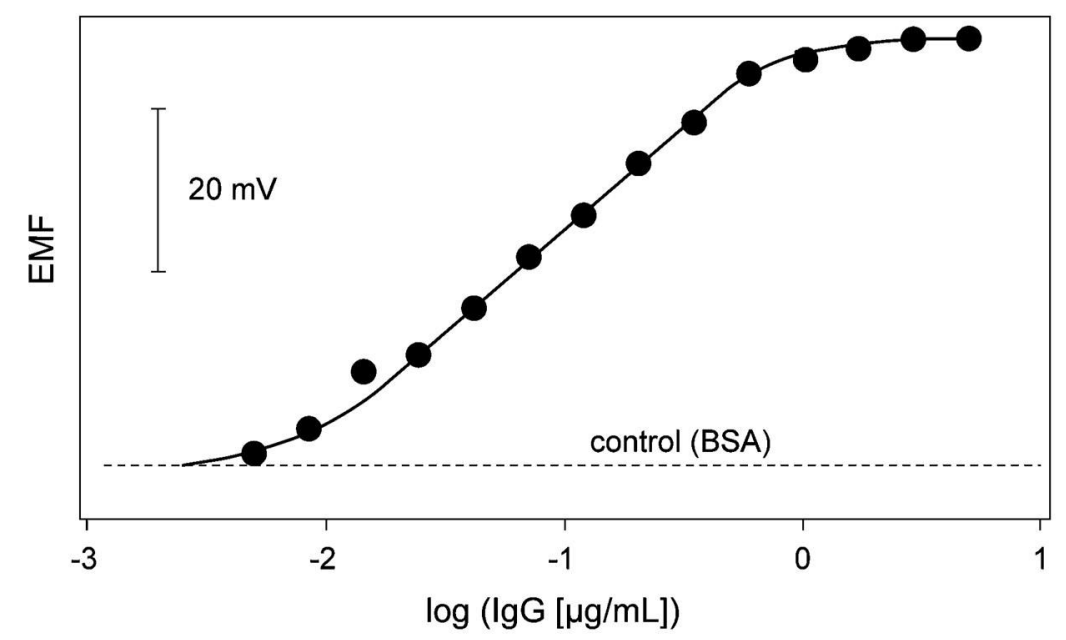

Figure 5.

Potentiometric monitoring of IgG concentrations via CdSe quantum dot labels in $150-\mu \mathrm{L}$ microvials with the sandwich immunoassay (cf. Figure 4). Dotted line: Signal obtained with BSA instead of target protein (shown as control). 